\title{
Internet Dependency among University Entrants: A Pilot Study
}

\author{
Arjunan, N. K. ${ }^{1 *}$, Moncy Edward ${ }^{1}$
}

Keywords: Internet Dependency, University, Entrants

The use of the internet has expanded incredibly across the world over the last few years. The internet provides remote access to others and abundant information in all areas of interest. However, maladaptive use of the internet has resulted in impairment of the individual's psychological well-being, academic failure and reduced work performance (Koet al., 2009; Fisher, 2010., Christakis, 2010; Chou et al., 2005; Young, 1998; Morahan\& Schumacher, 2000; Scherer, 1997). Cao et al. (2007) reported internet addiction disorder (IAD) as one of the common mental health problems amongst Chinese adolescents which is currently becoming more and more serious.

Internet addiction (internet dependency) is considered a psychological problem worldwide since it has a negative effect on behavior, such as preventing social interactions and reducing academic performance (Scherer, 1997; Morahan-Martin \& Schumacher, 2000; Young, 1998) impairing personal functions(Tsai \& Lin, 2003), and harming personal relationships(Beard, 2002). Among the people threatened with the excessive internet use, university students are considered as a potential group for investigating internet addiction. Free and unlimited internet access, long periods of unstructured time, newly experienced freedom from parental control, no monitoring or censoring of what they say or do online, full encouragement from faculty and administrators, social intimidation and alienation, are all possible reasons for internet addiction among university students. Uncontrolled and excessive use of the internet may result in negative consequences in the lives of this group. Correspondingly, this problem has received close attention from educators, psychologists and psychiatrists, since internet addiction intervenes with interactions with other people, academic achievement, psychological wellbeing, interpersonal and marital adjustment (Engelberg, \&Sjöberg, 2009;Morahan-Martin \& Schumacher, 2000).

The present study aimed to collect information about internet dependent behaviour of a group of first year degree students. Specifically, the study focused on whether there were any differences

\footnotetext{
${ }^{1}$ Research \& Development Centre, Bharathiar University, Coimbatore, India

*Responding Author

(C) 2016 I N Arjunan, M Edward; licensee IJIP. This is an Open Access Research distributed under the terms of the Creative Commons Attribution License (http://creativecommons.org/licenses/by/2.0), which permits unrestricted use, distribution, and reproduction in any Medium, provided the original work is properly cited.
} 
in the students' internet usage behaviour according gender, locale of residence, and stream of study.

\section{OBJECTIVES}

1. To find out the proportion of university entrants in various levels of internet dependency.

2. To find out any significant difference between the internet addiction scores of university entrants with respect to gender.

3. To find out significant differences, if any, among students from different residential areas with regard to their internet dependent behaviour.

4. To find out the differential influence of academic stream of study on the internet addiction behaviour of university entrants.

\section{Hypotheses}

The following specific hypotheses were formulated for the purpose of the study:

1. $\mathbf{H}_{1}$ : The university entrants of Kerala do not have severe internet dependency.

2. $\mathbf{H}_{2}$ : There will not be any significant gender difference in the internet dependent behaviour of university entrants of Kerala.

3. $\mathbf{H}_{3}$ : Locale of residence will not discriminate the internet dependent behaviour of university entrants of Kerala.

4. $\mathbf{H}_{4}$ : The internet dependent behaviour of university entrants of Kerala do not differ significantly based on their stream of study.

\section{METHODOLOGY}

Normative survey method was used in the present study. The study made use of a sample of 264 first year undergraduate students (male $=120$ male, and female $=144$ ) from different streams of study (Arts, Science, Engineering and Medical), selected on the basis of 'stratified random sampling technique' from Ernakulam district, Kerala. The average age of the subjects were estimated to be 18.43 .

\section{Tools used}

1. The Internet Addiction Test (IAT): The internet dependent behaviour of the subjects was assessed with the 20-item Internet Addiction Test (Young, 1996). The test measures the extent of an individual's involvement with the internet and classifies the addictive behavior in terms of mild, moderate, and severe impairment. The IAT was developed based upon behavioral indicators that distinguish dependent from non-dependent Internet users. The final score is obtained by summing the scores of all items. The higher score represents a greater level of addiction. The total score between 20 and 49 represents a mild addiction, 50-79 represents moderate addiction, and 80-100 represents severe addiction. The IAT demonstrated moderate to high internal consistency with Cronbach’s alphas ranging from .54 to 82 .

2. The General Data Sheet: The socio-demographic information required for the study was collected by attaching a General Data Sheet developed by the investigators for the purpose of the study. 


\section{Procedure}

The tool was administered on the sample in group situation under standardized conditions, their responses were collected in the response sheets, and the total score on the IAT was found out. The data thus obtained were subjected to appropriate statistical techniques and interpreted accordingly. The descriptive statistical indices the total sample and relevant sub-samples were computed and the group comparisons were done by applying t-test or ANOVA with the help of SPSS (Windows 16.0).

\section{RESULTS AND DISCUSSION}

The present study is aimed at understanding the internet dependency among university entrants. The data collected by administering the IAT is analyzed by keeping the specific objectives and hypotheses in mind. The details of the analysis carried out in this context are given below:

\section{Internet Dependency of University Entrants}

An attempt is made in this section to examine the internet dependency of University entrants of Kerala, considering the sample as total group as well as the sub-samples based on gender, locale and stream of study. The important statistical indices such as Mean (M), Median (Mdn), Standard Deviation $(\sigma)$, Skewness (Sk), Kurtosis, Standard Error of Mean ( $\left.\mathrm{SE}_{\mathrm{M}}\right)$ and population values of the Mean $\left(\mathrm{M}_{\mathrm{POP}}\right)$, calculated from the Digital Dependency Scores of the total group and the sub-samples are presented in Table 1.

Table 1: Statistical Indices of IAT Scores of University Entrants (Total Sample and Subsamples)

\begin{tabular}{|c|c|c|c|c|c|c|c|c|c|c|}
\hline \multirow{3}{*}{$\begin{array}{l}\text { Statistical } \\
\text { Indices }\end{array}$} & \multirow{3}{*}{$\begin{array}{l}\text { Total } \\
\text { Sample }\end{array}$} & \multicolumn{9}{|c|}{ Sub-samples } \\
\hline & & \multicolumn{2}{|c|}{ Gender } & \multicolumn{3}{|c|}{ Locale } & \multicolumn{4}{|c|}{ Stream of Study } \\
\hline & & Male & Female & Rural & Urban & Metro & Arts & Scin. & Engg. & Medic \\
\hline $\mathbf{N}$ & 264 & 120 & 144 & 155 & 102 & 47 & 72 & 60 & 79 & 53 \\
\hline Mean & 34.65 & 37.37 & 32.77 & 28.59 & 38.15 & 43.06 & 30.25 & 34.73 & 37.43 & 36.40 \\
\hline Median & 29.00 & 32.00 & 27.00 & 24.00 & 32.00 & 41.00 & 25.00 & 29.00 & 32.00 & 32.00 \\
\hline Mode & 19 & 16 & 19 & 16 & 22 & 19 & 19 & 22 & 16 & 22 \\
\hline Range & 78 & 77 & 77 & 61 & 75 & 77 & 63 & 76 & 77 & 70 \\
\hline SD & 17.92 & 19.27 & 16.96 & 14.49 & 18.14 & 21.23 & 15.42 & 18.50 & 19.44 & 17.41 \\
\hline Skewness & 1.10 & 0.97 & 1.18 & 1.40 & 0.95 & 0.65 & 1.25 & 1.26 & 0.97 & 0.904 \\
\hline Kurtosis & 0.54 & 0.15 & 0.68 & 1.26 & 0.19 & -0.59 & 0.84 & 0.97 & 0.19 & 0.169 \\
\hline $\mathrm{SE}_{\mathrm{M}}$ & 1.10 & 1.76 & 1.41 & 1.35 & 1.79 & 3.09 & 1.82 & 2.39 & 2.19 & 2.39 \\
\hline $\mathbf{M}_{\text {POP } .05}$ & $\begin{array}{l}32.49 \\
36.81\end{array}$ & $\begin{array}{l}33.92 \\
40.84\end{array}$ & $\begin{array}{l}30.01 \\
35.53\end{array}$ & $\begin{array}{l}25.94 \\
31.24\end{array}$ & $\begin{array}{l}34.64 \\
41.66\end{array}$ & $\begin{array}{l}37.00 \\
49.12\end{array}$ & $\begin{array}{l}26.68 \\
33.82\end{array}$ & $\begin{array}{l}30.05 \\
39.41\end{array}$ & $\begin{array}{l}33.14 \\
41.72\end{array}$ & $\begin{array}{l}31.72 \\
41.08\end{array}$ \\
\hline $\mathbf{M}_{\text {POP }} .01$ & $\begin{array}{l}31.81 \\
37.49\end{array}$ & $\begin{array}{l}32.83 \\
41.91\end{array}$ & $\begin{array}{l}29.13 \\
36.41\end{array}$ & $\begin{array}{l}25.11 \\
32.07\end{array}$ & $\begin{array}{l}33.53 \\
42.77\end{array}$ & $\begin{array}{l}35.09 \\
51.03\end{array}$ & $\begin{array}{l}25.55 \\
34.95\end{array}$ & $\begin{array}{l}28.56 \\
40.90\end{array}$ & $\begin{array}{l}31.78 \\
43.08\end{array}$ & $\begin{array}{l}30.23 \\
42.57\end{array}$ \\
\hline
\end{tabular}


The data presented in Table 1 shows that as far as the internet dependent behaviour is concerned, the group under study is a heterogeneous one, since the highest score obtained is 91 and the lowest score obtained is 13 out of a maximum of 100 and a minimum of 0 . The mean of the IAT scores of the total sample under study is 34.65, with a standard deviation of 17.92. The median estimated for the distribution is 29.00 , which is lesser than the mean value producing a positively skewed distribution $(\mathrm{Sk}=1.10)$. The mean population value $\left(\mathrm{M}_{\mathrm{POP}}\right)$ will lie between 32.49 and 36.81 at 0.05 level; and between 31.81 and 37.49 at 0.01 level ( $\mathrm{SE}_{\mathrm{M}}$ for the total sample is 1.10). A closer observation of the result presented in Table 1 clearly indicates that various sub-samples show different trend in distribution.

Based on the norms of the IAT, the total sample was further classified into different levels of internet addiction viz., normal, mild, moderate and severe. The proportion of these four types of internet dependent groups in the total sample is given in Figure 1.

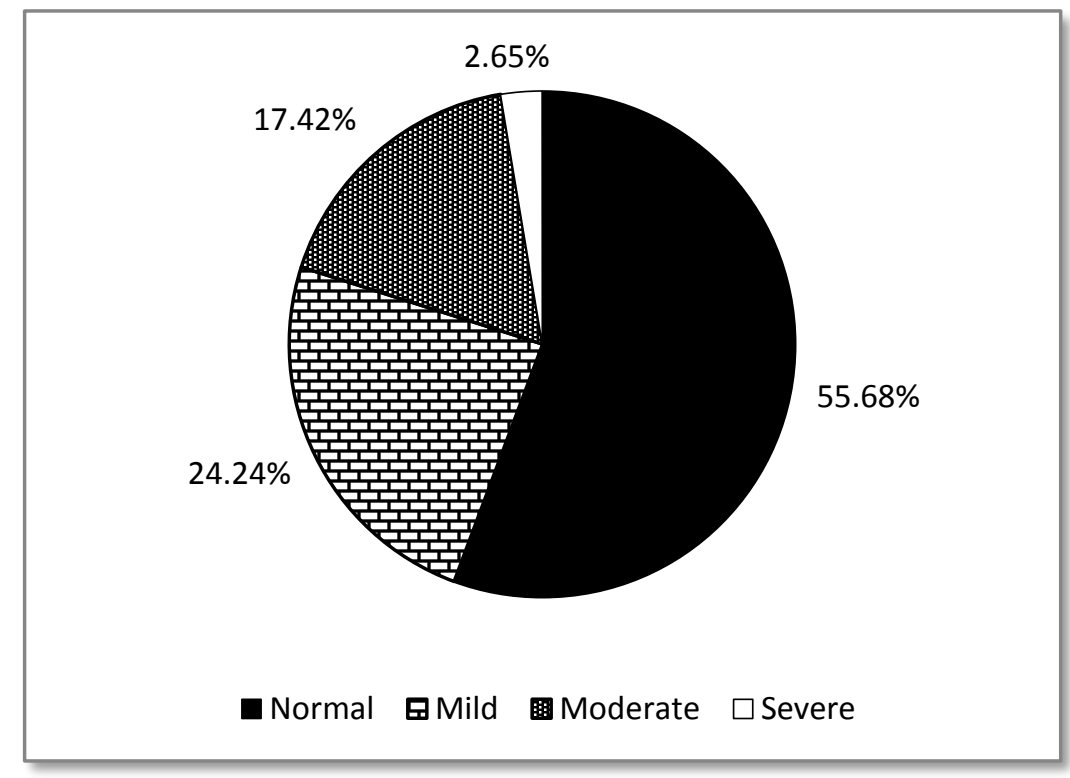

Figure 1: Proportion of Different Levels of Internet Dependency among University Entrants (Total Sample)

As evident from Figure 1, majority (55.68\%) of the university entrants in Kerala are normal with regard to their internet dependant behaviour. While $24.24 \%$ of the first year undergraduates are mildly addicted to internet, $17.42 \%$ is moderately dependent, and $2.65 \%$ of the subjects are severely addicted to internet. 


\section{Comparison of the Internet Dependent Behaviour of Sub-samples}

It was one of the research questions to study the differential distribution of IAT scores in male and female students. The proportion of different levels of internet addiction behaviour in the gender groups are given in Figure 2.

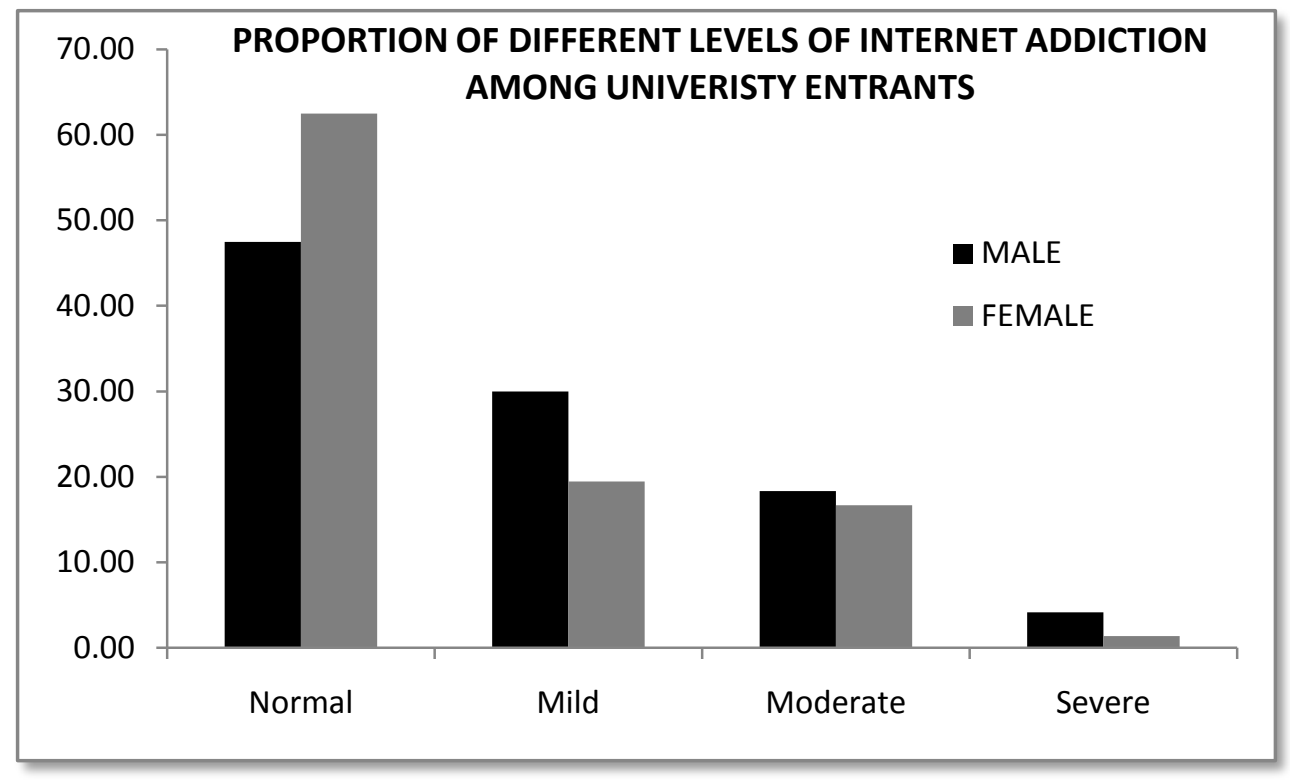

Scrutiny of figure 2 indicates that male and female students are not alike in the distribution of IAT scores in different levels of internet dependent behaviour. In order to find out whether there exists a real difference between male and female students with regard to their internet dependent behaviour, the groups were compared by applying the two-tailed test of significance for difference between means. The details of the comparison are presented in Table 2 .

Table 2: Comparison of the IAT Scores of the Sub-samples based on Gender

\begin{tabular}{|l|l|l|l|l|l|}
\hline \multirow{2}{*}{ Groups } & \multirow{2}{*}{ Sub-samples } & \multicolumn{3}{|l|}{ Statistical Indices } & \multirow{2}{*}{ t-value } \\
\cline { 3 - 6 } & & $\mathbf{N}$ & $\mathbf{M}$ & SD & \\
\hline \multirow{2}{*}{ Gender } & Male & 120 & 37.08 & 19.000 & \multirow{2}{*}{$2.02^{*}$} \\
\cline { 2 - 5 } & Female & 144 & 32.63 & 16.769 & \\
\hline
\end{tabular}

The $t$-value obtained on comparing the gender groups is significant $(t=2.02 ; \mathrm{p}<0.05)$, indicating that the male and female students in the first year undergraduate classes are not alike in their 
internet dependent behaviour. A closer observation of the data presented in Table 2 makes it clear that the male students are more dependent on internet than their female counterparts.

It was of research interest to find out the differential effect of locale of residence on internet addiction behaviour of the university entrants. The sample selected for the study comprises subjects from rural, urban as well as the metro city of Cochin. The distribution of the IAT scores of the subjects from the above three residential areas are shown in Figure 3.

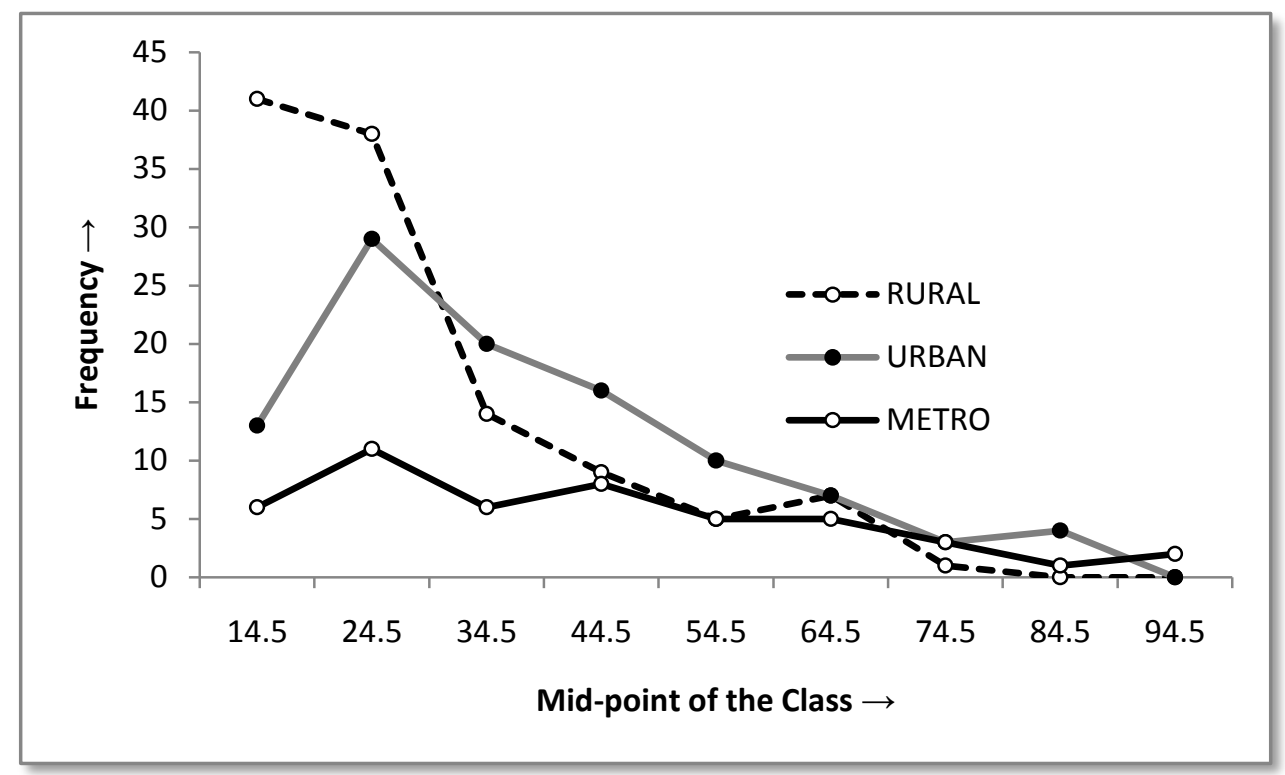

Figure 3: Distribution of IAT Scores in Sub-sample based on Locale of Residence

The curves of distribution of internet addiction (vide Figure 3) for different residential groups remain different, leaving the lacuna for further statistical analysis to establish the existence of real difference in the population. On way ANOVA was, thus, run to find out whether there exist significant differences in the mean IAT scores among the groups compared. The data and result of the ANOVA are given in Table 3.

Table 3: Comparison of IAT Scores of Residential Groups (Result of ANOVA)

\begin{tabular}{|l|l|l|l|l|l|}
\hline IAT & Sum of Squares & df & Mean Square & F & Sig. \\
\hline Between Groups & 8544.144 & 2 & 4272.072 & & \\
\hline Within Groups & 75919.795 & 261 & 290.880 & 14.687 & .000 \\
\hline Total & 84463.939 & 263 & & & \\
\hline
\end{tabular}

The F-value obtained (vide Table 3) is significant at .01 level and above, indicating that there exists a real difference among the groups with regard to their IAT scores. To put it differently, 
the internet addiction behaviour of university entrants of Kerala varies according to the locale if residence. This makes further analysis indispensable to find out the groups which differ significantly. The Tukey's post hoc test of intergroup comparison was carried out so as to find out the group-pairs which differ significantly. The data and result of the analysis is given in Table 4.

Table 4: Post Hoc Tests for Comparisons of the Internet Addiction in Locale Groups

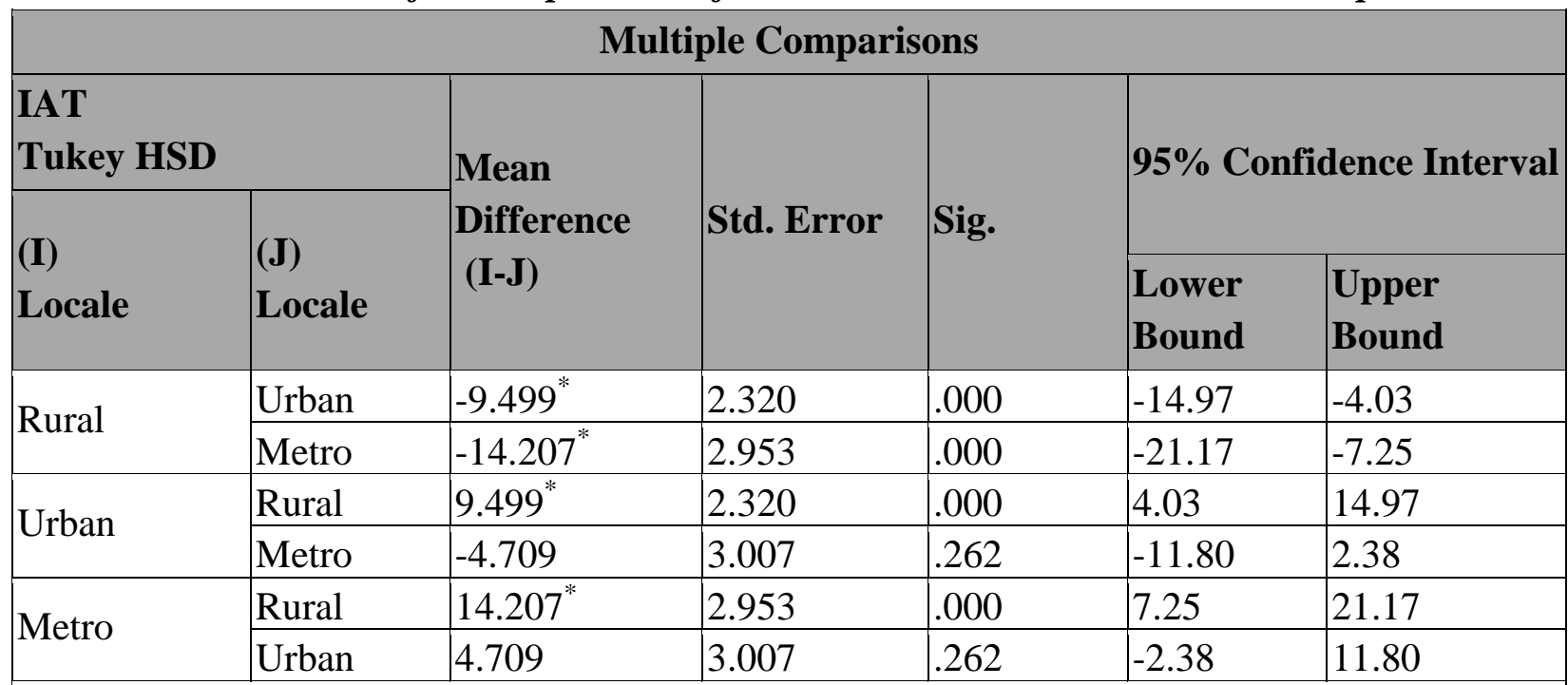

*. The mean difference is significant at the 0.05 level.

The result of the Tukey post-hoc test revealed that significant differences exist between two pairs of groups compared viz., Rural-Urban and Rural-Metro, No significant difference exist between the internet addiction behaviour between the urban and metro students.

Another important concern of the present investigation was to find out whether the stream of study has got any influence on the internet addiction behaviours of the subjects. Accordingly, intergroup comparison of the IAT scores of undergraduates pursuing degree programme in Arts, Science, Engineering and Medicine streams were compared by applying one way ANOVA. The data and result of the analysis carried out in this context is given in Table 5.

Table 5: Comparison of IAT Scores of Groups based on Stream of Study (Result of ANOVA)

\begin{tabular}{|l|l|l|l|l|l|}
\hline IAT & $\begin{array}{l}\text { Sum of } \\
\text { Squares }\end{array}$ & df & $\begin{array}{l}\text { Mean } \\
\text { Square }\end{array}$ & F & Sig. \\
\hline $\begin{array}{l}\text { Between } \\
\text { Groups }\end{array}$ & 2166.660 & 3 & 722.220 & 2.282 & .080 \\
\cline { 1 - 3 } $\begin{array}{l}\text { Within } \\
\text { Groups }\end{array}$ & 82297.280 & 260 & 316.528 & \\
\hline Total & 84463.939 & 263 & & \\
\hline
\end{tabular}


The estimated F-value is not significant at .05 (vide Table 5, $\mathrm{F}=2.282 ; \mathrm{P}>0.05$ ), showing that students doing their course in Arts, Science, Engineering and Medicine are almost alike in the behaviour related to internet dependency. To state in other words, the stream of course the undergraduates pursue is not a significant factor contributing to their Internet behaviour.

\section{CONCLUSIONS}

The present study revealed that only $2.65 \%$ of the subjects fall in the severe range of internet addiction. Majority of them (55.68\%) belongs in the normal range. The hypothesis formulated in this context, viz., $\mathrm{H}_{1}$ (the university entrants of Kerala do not have severe internet dependency) is, hence, accepted. Comparison of male and female undergraduates revealed that there exist a gender difference with regard to the internet dependent behaviour of university entrant $(\mathrm{t}=2.02$; $\mathrm{p}<0.05)$. The male students are more addicted to internet than their female counterparts. The hypothesis formulated in this connection $\left(\mathrm{H}_{2}\right.$ : There will not be any significant gender difference in the internet dependent behaviour of university entrants of Kerala) is hence rejected. The Fvalue obtained on comparing the rural, urban and metro students is significant $(\mathrm{F}=14.687 ; \mathrm{p}<$ .000) revealing that locale of residence is a significant factor that decides the internet addiction behaviour of university entrants. The hypothesis formulated in this regard $\left(\mathrm{H}_{3}\right.$ : Locale of residence will not discriminate the internet dependent behaviour of university entrants of Kerala) is hence rejected. The ANOVA run to compare the IAT scores of the students based on the stream of their study showed that groups are alike with regard to their internet dependent behaviour. The fourth hypothesis (the internet dependent behaviour of university entrants of Kerala do not differ significantly based on their stream of study) is, hence, accepted.

\section{REFERENCES}

Beard, K. W. (2002). Internet addiction: current status and implications for employees. Journal of Employment Counseling, 39: 2-11.

Beard, K. W. (2005). Internet addiction: A review of current assessment techniques and potential assessment questions. Cyber psychology \&Behavior, 8(1): 7-14.

Cao F, Su L, Liu T, Gao, X. (2007). The relationship between impulsivity and Internet addiction in a sample of Chinese adolescents. European Psychiatry, 22: 466-471.

Chou, C., Condron, L., \& Belland, J. C. (2005).A review of the research on internet addiction.Educational Psychology Review, 17(4): 363-388.

Christakis D (2010) Internet addiction: A $21^{\text {st }}$ century epidemic? BMC medicine 8: 61. Chou C., Condron, L., Belland, J. (2005). A review of the research on Internet addiction. Educational Psychology Review 17: 363-388.

Engelberg, E., \&Sjoberg, L. (2009).Internet use, social skills, and adjustment. Cyber psychology and Behavior, 7: 41-47.

Fisher, C. (2010). Getting plugged in: An overview of Internet addiction. Journal of Paediatrics and Child Health, 46: 557-559. 
Ko C, Yen J, Chen S, Yang M, \& Lin, H. (2009). Proposed diagnostic criteria and the screening and diagnosing tool of Internet addiction in college students. Comprehensive psychiatry, 50: $378-384$.

Morahan-Martin, J. \& Schumacher, P. (2000).Incidence and correlates of pathological internet use among college students. Computers in Human Behavior, 16: 13-29.

Scherer, K. (1997). College life on-line: healthy and unhealthy internet use. Journal of College Student Development, 38: 655-665.

Tsai, C., \& Lin, S. S. (2003). Internet addiction of adolescents in Taiwan: An interview study. Cyber Psychology \& Behaviour, 6(6): 649-652.

Young, K. (1998). Internet addiction: The emergence of a new clinical disorder. Cyber Psychology \&Behavior, 1: 237-244.

Young, K. S. (1996). Internet Addiction: The Emergence of a New Clinical Disorder. Cyber Psychology and Behavior, (1), 3, 237-244. 